\title{
Mediating Effects of Avatar Realism on Motivation in Game Based Learning - Review
}

\author{
Kogilathah Segaran ${ }^{1 *}$, Ahmad Zamzuri Mohamad Ali ${ }^{2}$, Wee Hoe Tan ${ }^{3}$ \\ 1,2,3 Faculty of Art, Computing and Creative Industry, \\ Universiti Pendidikan Sultan Idris, 35900 Tanjong Malim, Perak, MALAYSIA \\ *Corresponding Author \\ DOI: https://doi.org/10.30880/ojtp.2019.04.02.010 \\ Received 25 $5^{\text {th }}$ June 2018; Accepted $25^{\text {th }}$ May 2019; Available online $30^{\text {th }}$ September 2019
}

\begin{abstract}
Virtual environments and digital games are being increasingly used as educational tools in current education settings. For the past few decades there were tremendous amount of studies involving digital game based learning (DGBL) in many subject matters to identify best design approach to increase its effectiveness. DGBL have been expanded in several ways by referring to digital entertainment games such as in using avatar which would assist the students to revise and learn on their own. Usage of avatars as an educator in the virtual learning environment is increasing as its importance increases where interactivity, learner engagement, cultural factors, communication, embodiment and motivation are crucial design considerations in a virtual learning environment. Nevertheless, question arises as what type of avatar whould be preferred by the learners in DGBL. There were dearth studies conducted on how the realism level of an avatar in DGBL would influence the emotions of a learner since researchers stated that emotions practiced throughout a learning method offer clues not solely to the effectiveness of a learning activity however additionally to the method of learning. Likewise, there were scarcity in identifying the relationship between level of realism with different elements of emotions (valence and arousal) and different theories of motivation. Thus, this paper, critically reviews the literature related to usage of avatar in DGBL. This paper also discusses the finding related to motivation and emotion factors in DGBL, relation between realism in avatar and emotion, relation between motivation, emotion and realism of avatar in DGBL.
\end{abstract}

Keywords: DGBL, avatar, realism, emotion, motivation

\section{Introduction}

Educational digital games have become a huge research opportunity nowadays which has opened up plenty of research area for researchers to expand their ideas. It has also enabled players to immerse themselves into virtual world and acquire knowledge while having fun. Over the past decade, implementation of DGBL has impelled significant attention in exploring how and why games might be powerful tools in the classroom (An et.al, 2016; Groff, Howells \& Cranmer, 2010).

There are also growing bodies of DGBL research in Malaysia to enhance both tertiary and the secondary level students' knowledge acquisition. Nevertheless, in a virtual learning environment such as game based learning, learners tend to complain online learning feels unemotional and detached since the existence of an instructor or pal is missing to upkeep them through the coaching process. In order to overcome this problem virtual characters or avatars can be integrated to personalize the experience (Ratan \& Hasler, 2011). However, implementation of DGBL particularly assisted by an avatar seems lacking in teaching and learning in Malaysia. Thus, this review looks into various empirical studies on how an avatar can influence a DGBL setting in the context of avatar realism, emotion and motivation. 


\section{Games as Motivational Tool in Learning}

Motivation is the main component accredited about games. It has been highlighted as a mutual relation between games and players. Players have the natural action of willingly to play a game which is considered an intrinsic motivation (Uzun, Cetinavci, Korkmaz \& Salihoglu, 2013). This makes it possible that the motivation created by a game can also be reinforced by the players' motivation in playing the game (Uzun, Cetinavci, Korkmaz \& Salihoglu, 2013). By the same token, games in general and in particular digital games could potentially motivate players by building challenging, interesting and demanding atmosphere in which players acquire the opportunity to interact in order to fulfill their necessities. Henceforth, games are treated as highly motivating means of educational tool (Evans, Jones, \& Akalin, 2017; Franciosi, 2011; Ersöz, 2000; Yee, 2006; Batson \& Feinberg, 2006).

Motivation is vital for effective learning. Nevertheless, Clement (2017) and Ellis (2001) stated that it may alter for a learner in due time as it will be affected by external factors. Yet, the condition is slightly different for digital games as the motivation is internal and mutual, and perhaps lasts longer than other types of motivation. Combinations of games and technology have a tendency to form an intrinsic motivation whereby it was examined by the prin ciples of 'Flow Theory (Franciosi, 2011). As such, player involves themselves not by force but because of their own interest. A huge number of young adults spend numerous hours a week playing computer games, and this would open a new horizon for games as an educational tool since it portrays the motivation to retain in the game (Dai \& Fry, 2014; Kickmeier-Rust \& Albert, 2010). Adding to that, an estimation of 10,000 hours being spent by the youth before they attain 21 years (Prensky, 2003). However, others have debated that game-based learning might not produce positive learning outcomes even though video games proven to enhance motivation for learning (Baretto, Vasconcelos 7 Orey, 2017; Rankin, Gold, \& Gooch, 2006). DGBL studies have adopted two types of games, which are commercial software and newly designed and developed (Huang, 2011; Yang, 2012; Liu \& Chu, 2010; Kebritchi et al., 2010; Papastergiou, 2009). Both of these categories capable of stimulating the element of motivation in learning, nevertheless newly designed and developed software need to follow explicit instructional objectives in order to fulfill the requirement of current curriculum.

How? When? To what extend the contribution of games? In order to know this, further research needed to affirm on games capability in contributing to the motivation of learners, knowledge and education. One of the ways to improve learning performance or to retain students in the DGBL environment is by having an online teacher or coach or a mentor to motivate them.

\section{Avatar in Game-Based Learning}

Virtual characters in digital game have appeared as early as in 1970s (Haake, 2009). Retro game such as Space Invaders has the virtual characters in the form of aliens (Fig.1). Later on in the 1980s, there was a breakthrough in video game history with another retro game called Pac-Man, (Fig.2) where it introduced more social interactive virtual characters.

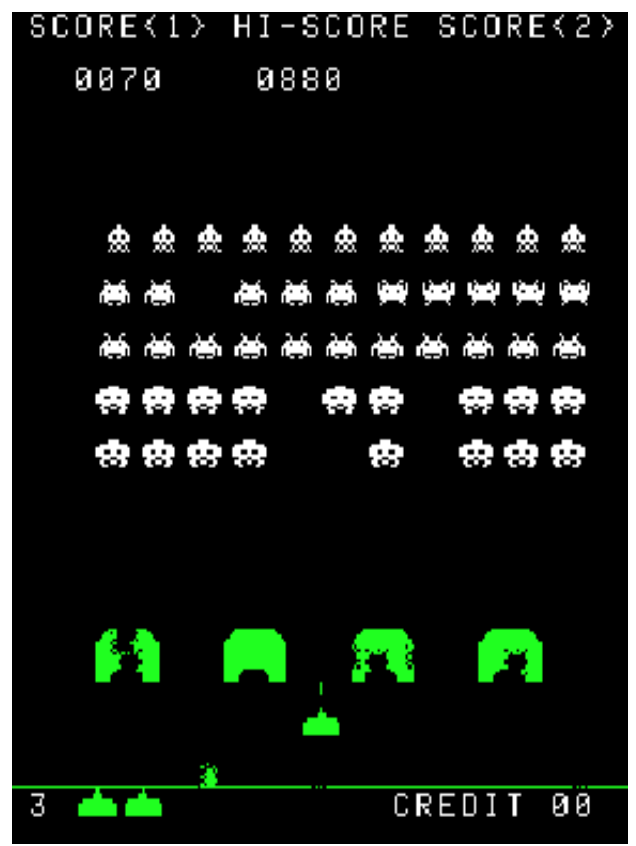

Fig.1 - Space Invaders by Taito Corporation 


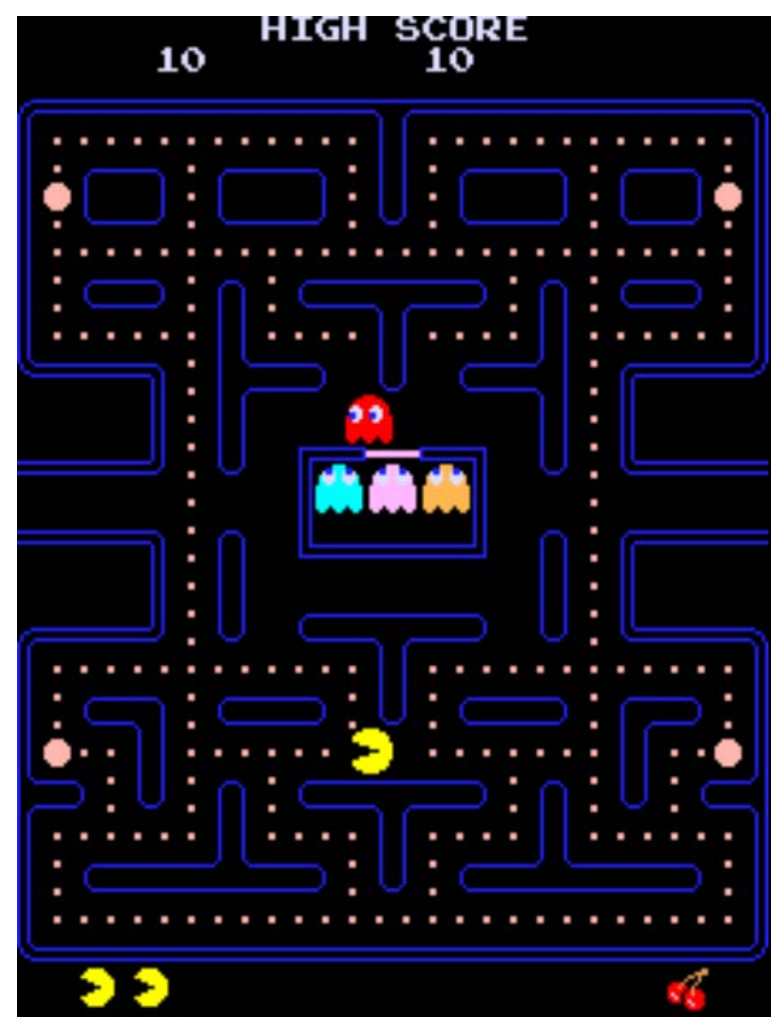

Fig.2 - Man by NAMCO BANDAI Games America Incorporation

This development continued till users interact with embodied virtual characters such as avatars in multiplayer online games, interactive chat bots and embodied pedagogical agents in virtual tutoring (Fig.3 and Fig.4) (Haake, 2009).

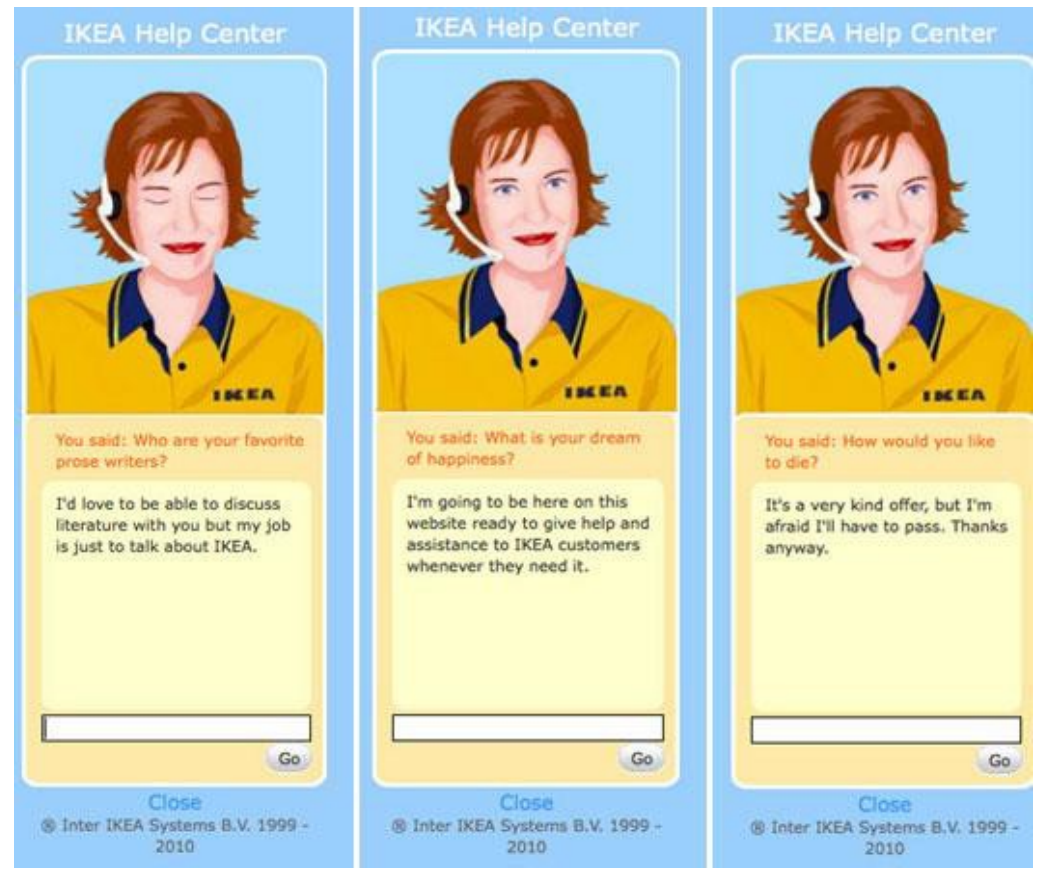

Fig.3 - IKEAs chat bot Anna in inter IKEA systems B.V 


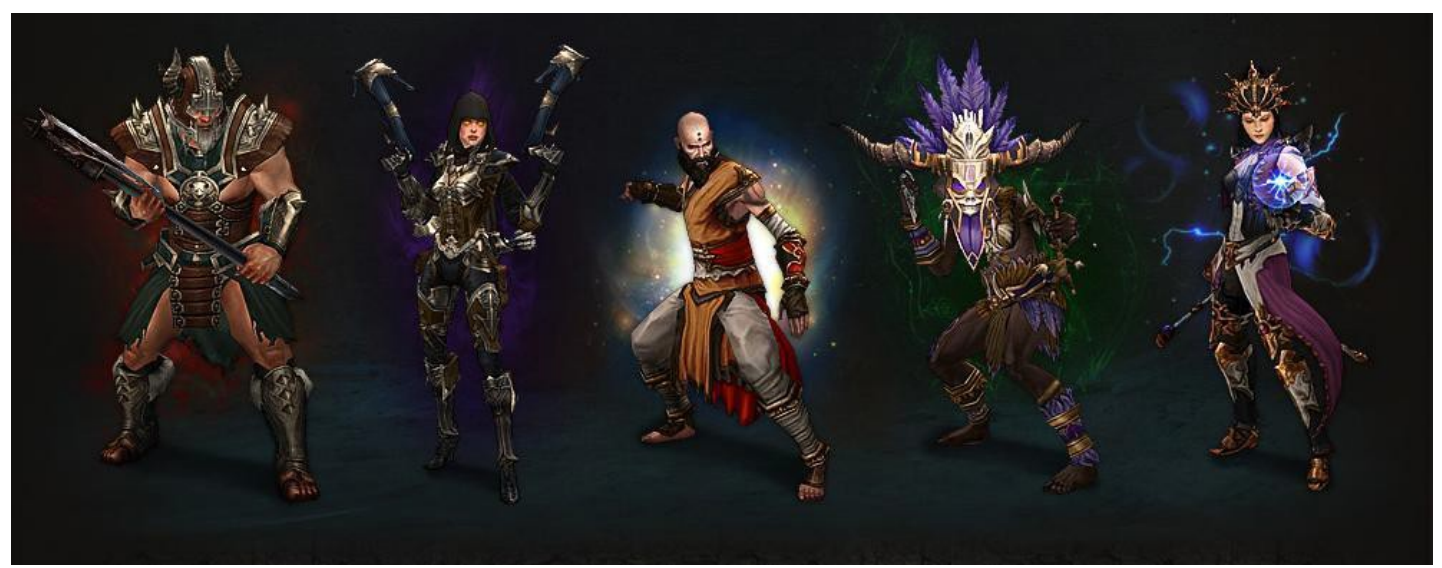

Fig.4 - Avatar in Diablo III @ 2016 Blizzard Entertainment, Inc.

As such, it can be claimed, over the time the virtual characters have evolved from simple less detailed characters such as Pac-Man to intelligent and autonomous detailed characters that can be found in digital games. Adding to that, with each newly designed digital character, the boundary between reality and virtual reality is becoming scattered. In consequence, this method and technology is being spread into virtual academia whereby, usage of avatar in virtual learning has peaked over the last decade. Many refer avatar as pedagogical agent in virtual learning as it is claimed to be a fancy word for characters in e-learning (Kapp, 2014).

Avatar as pedagogical agent has been widely used in e-learning and in digital game based learning. In earlier stage, students who use e-learning only see the interface that has been designed to facilitate interaction with the application (Schroeder, Adesope \& Gilbert, 2013; Sheth, 2003). Different design and techniques have been used in order to give the best facilitation to the students where some might have worked but some failed. In order to overcome this scenario, avatar has been introduced to provide an engaging, personalized, and simple interface (Shaked, 2017; Sheth, 2003). Starting with chatbots and infobots, to automated virtual newsreaders, avatars are now easily expanded its usage in e-learning programs (Schroeder, Adesope \& Gilbert, 2013; Sheth, 2003). On the other hand, usage of avatar has also expanded to DGBL in which, virtual space representing a classroom in game-based learning, avatar is preferred to represent a real educator (Mert \& Samur, 2018; Inal \& Cagiltay, 2006). This is because educators believed that it will increase the students' motivation while acquiring knowledge on their own (Romero \& Glass, 2015; Inal \& Cagiltay, 2006).

By the same token, one of the most important impact of using avatar is that they have features to engage and facilite interaction for effective communication between learners and the virtual classroom (Christopoulos, Conrad \& Shukla, 2018; Craig, Driscoll Gholson, 2002). Human like avatars can also support learners to acquire postive impact in learning performance (Huang \& Liaw, 2018; Baylor, 2000). Adding to this, in a study conducted by Johnson, Rickel and Lester (2000) suggested that human like avatars having many characteristics are optimal to serve as tutors, coaches, or guides in game-based learning environments to provide knowledge based facilities to the learners. Following this, several studies have been conducted to reveal what type of avatar would suit a learning environment as some research stated realistic character would give a positive impact on cognitive tasks and some research stated that cartoon like character would give a cozy feeling to the learners which eventually motivate them to acquire knowledge.

\section{Realism in DGBL Avatar}

Avatar or virtual character in DGBL has gone through numerous developments and research to suit the players need. Recent technology improvement has paved way for animators and game designers to create highly realistic virtual characters (Tinwell, 2015). Increased in realism has proved to certain extend that would grant the viewer to engage and enjoy the game that they are playing (Hoggins, 2010; Ravaja et. al., 2008; Doerr, 2007). However, MacDorman, Green, Ho, and Koch (2009) mentioned in their studies, users tend to feel disturbed when a virtual character appearance is too human like or too realistic. Moreover, "increased in realism does not necessarily mean increased approval and factors such as abnormal facial expression may evoke the Uncanny Valley phenomenon" (Tinwell, 2013).

Then again, a few examinations have investigated the impact of the virtual character presence or the virtual character stage of authenticity on learning. In this case, an effort was taken to look at the effect of two types of realism in virtual character (realistic and cartoon) (Baylor \& Kim, 2004). It was identified, that students who utilized realistic character showed enhanced execution and beneficial outcomes contrasted with those who utilized the unrealistic character (cartoon appearance) in their learning. Moreover, a study found that nearly all students picked the "iconic agent", trailed by the "moderately realistic" and finally, the "highly realistic" agent (Gulz \& Haake, 2005). Likewise, in another study it was found that the students' use of "highly realistic" or "unrealistic agent" resulted negative contrasts in the scores of their accomplishment (Moreno et al., 2001). Their outcomes demonstrated that a "highly realistic" design did not mean generally an essential part for a persuasive agent in learning (Dalibard, et. al., 2012; Clark \& Mayer, 2003; Heinich et al., 1993). 
Norman $(1994 ; 1997)$ also stated that a virtual character that is designed with too humanlike, likely to outline unrealistic hope in which, a too realistic humanlike interaction and appearance can be untrustworthy and deceptive by affirming functionality that unable to be achieved. On the other hand, virtual characters without any difference in virtual from humans (Ma, et.al., 2017; Vassileva, et.al., 1998; Hays-Roth \& Doyle, 1998; Rizzo, 2000) and capable to aggravate 'illusion of life' will impress the learners in interacting with the virtual characters more sufficiently. At the same time, learnes will accept the character willingly when their expectation matches its real functionality (Tinwell, 2013; Norman 1994; 1997).

Meanwhile, studies proven that appearance of a virtual character are crucial if a learner needs to accept and also to evaluate it (Krämer, Rosenthal-von der Pütten \& Hoffmann, 2015; Domagk, 2010). Domagk (2010) also indicated that whilst the appearance is preferable, an avatar has more positive effects. Likewise, Strafling, Fleischer, Polzer, Leutner and Kramer (2010) also run a comparison test on a virtual tutor which appearance is based on either a cartoon-like rabbit character or a realistic humanlike agent. From the research, it is affirmed that the rabbit-like agent was preferred, and eventually users retain themselves in the tutoring session longer when the character gave response. Studies that focused more on integrity instead of learning and likeability, resulted that characters that are more humanlike are assumed as more convincing (Nowak \& Rauh, 2005). It can be concluded that there is sufficient proof in stating physical appearance of virtual character influence the way users react towards it. Nonetheless, even though many studies giving priority in researching into different enormity of appearance such as realism, anthropomorphism, and likeability, but physical appearance is still considered decisive. Therefore, question arises as how realistic avatar images should be designed to establish comfortable relations among learners and the character. Question also arises on to what extent of avatar realism will influence learners' emotion and motivation.

\section{Emotions and Realistic Avatar}

Introducing virtual character or well known as pedagogical agent or avatar into virtual learning to assist learners is being a trend now. These characters are also considered as virtual robots which also inherit the traits of being realistic and possess the element of uncanniness. As such, learners' emotions towards the character need to be looked into as it might influence the motivation. People's attitudes toward artificial character or virtual character generally affect their willingness to accept them. Negative attitudes and anxiety toward artificial character or virtual character affected human responses toward them and prefer to distance themselves (Ma, et.al., 2017; Nomura, Shintani, Fuji, \& Hokabe, 2007). Following that, even in the early research, Mori (1970) observed that an artificial character that has appearance and behavior simulating a real human reduced their acceptance towards the artificial character. This was due to perceived anomalies between the artificial human-like appearance and its behavior, therefore it regarded as strange. The artificial human-like appearance raised expectations that it would behave as a human, and failure to do so evoked a negative emotional response from the viewer to the extent of disgust.

In an examination directed by Bailenson et al. (2005) and Pan, Gillies and Slater (2015), they expressed that the participant was more reluctant in moving toward the agent with more human-like actions. Other than that, in two research it was found that participants had a tendency in receiving generally adequate spatial behaviour with virtual characters that showed feelings (de Borst \& de Gelder; 2015; Vinayagamoorthy et al., 2008). Whereas, in another test revealed participants were thoughtful by the existence of others when carrying out a chore, regardless of whether those others were virtual realistic character (Zanbaka et al., 2007). Vinayagamoorthy et al. (2008) contended that in an appearance and actions, the character needs to embrace a persuading structure. Moreover, Lee et al. (2002); Garau et al. (2003); and Vinayagamoorthy et al. (2004) mentioned the character should offer input to the participants at any rate through eye stare. However, the research did not look into the aspect of generating appropriate behavior, but rath er the personality context in which the realism of the character matters. In contrast, in a study conducted by Kokkinara and McDonnell (2015), it is mentioned that as oppose to theory of Uncanny Valley, the user rated a character with realistic face similarly appealing to the cartoon face in both animation realism conditions by and also shown positive emotions towards the virtual character (Fig.5). However, the study did not mention the level of realism of the acceptable virtual character by the user.
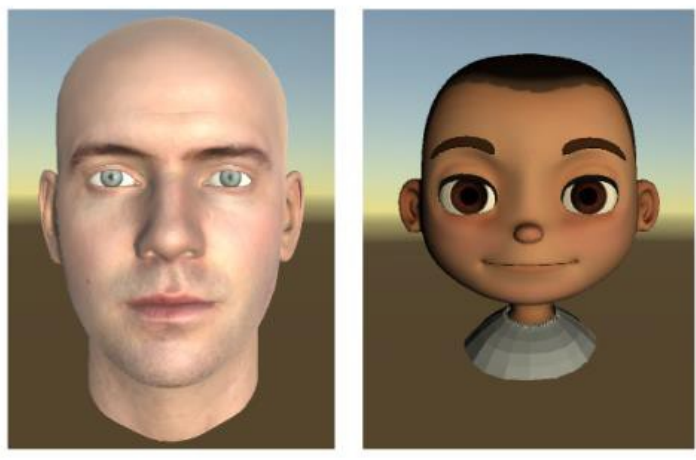

Fig.5 - Self-avatar faces. right: cartoon face. left: realistic face. (Kokkinara \& McDonnell, 2015) 


\section{Motivation and Emotions in Game-Based Learning}

Cognition, memory, attention and motivation has a strong relation with emotion but the current invention of educational games fundamentally ignore its' importance in learning (Wilkinson, 2013). However, there is a association within games development for entertainment to create more affective gameplay (Wilkinson, 2013). Normally, games integrate various emotions such as joy, curiosity and frustration (Pesare, Roselli, Nicola \& Veronica, 2016). Habitually, it is both positive and negative experiences being experienced by the players, whereby it motivates the players to transform and use them (Pesare, Roselli, Nicola \& Veronica, 2016). For instance, games usually have the tendency to make the player experience failure and usually the player seems to learn how to play by repeating the condition several times (Pesare, Roselli, Nicola $\&$ Veronica, 2016). The players will learn every time they retry. With this in mind, the game usually equipped with rapid feedback to motivate the player to retry until succeed and also to retain in the game (Pesare, Roselli, Nicola \& Veronica, 2016).

Moreover, engagement is frequently associated with a motivational angle (Pesare, Roselli, Nicola \& Veronica, 2016). Now and then the terms are utilized conversely, while Reschly and Christenson (2012) consider as needy builds. Engagement can be viewed as the presence of learners' inspiration (Schunk and Mullen 2012; Skinner et al. 2009) or as a multiple combination of game elements that incorporates both intellectual and motivational viewpoints (Dichev \& Dicheva, 2017). However, it needs further research as what kind of environment would emotionally influence the player to affirm whether emotions could be mediation for students' motivation.

\section{Motivation and Realism}

Virtual characters long have been proven to motivate learners in e-learning and games. Humanlike virtual avatars can provide as influential technological mediators to stress on motivational contribution such as self-efficacy and behavior change (Baylor, 2011; Baylor, 2009). Mainly, the visual presence and appearance of such avatars can have a major impact on motivation and affect regardless of the fundamental technical sophistication (Baylor, 2011; Baylor, 2009). However, the appearance of the avatar or pedagogical agent seldom being discussed even though it does relate to the valence of the presented social cues that might play a significant role (Domagk, 2010). Base on the experiment done by Domagk (2010) on whether the appeal of the virtual character appearance affect learner motivation and learning outcomes found that, the valence of the social cues (appearance and voice) did not affect learner motivation at the beginning and throughout the learning process. Therefore, the potential motivating effect of the realistic virtual character needs further examination which might be emotions of learner. This would be the focus of the study.

As a matter of fact, identification with a learner avatar may escalate the level of arousal and motivation in a virtual environment (Bailey et al., 2014). Bailey et al. (2014), had a child playing a simple game that involved an avatar that was either assigned, chosen by the child from a pool of avatars or customized by the child. The study resulted in motivating the child to sustain in the game and to proceed further. Inserting an anthropomorphic or humanlike avatar as the principle mean for the cause of motivation, it is important to have watchful thought to outline as the humanlike appearance that may sincerely impact the student. Research affirms that for affective and motivational results specifically, the visual occurrence of the character is vital. At the end of the day, a voice alone with the same influential message is not adequate. Baylor and Ryu (2003) found that giving an anthropomorphic avatar (either static or vivified) together with a human voice prompted more prominent student view of agent validity with regards to a learning domain. More recently, tertiary students who interact with visibly available agent portray significant positive motivational output (Baylor, 2011; Baylor, 2009).

In general, it is not denied that there are benefits in incorporating visually present avatar which is capable of delivering persuasive and soothing messages, however, the design of the physical appearance need to be considered (Baylor, 2009). As such, further study needs to be conducted in identifying the level of realism and emotions influence the motivation level of a learner. Therefore, this research is conducted to fill this gap.

\section{Conclusion}

Presently, games have been integrated in education to form an innovative educational prototype. Digital game which is an interactive technology within the multimedia learning environment could cultivate learning process effectively and interestingly among learners. However, in a game based learning environment, learners tend to feel lost without any formal instruction as they perceive through the traditional class. To overcome this, an avatar can be included with the consideration on the effect of it towards students' motivation and emotion in playing the game and perceiving the intended knowledge.

\section{Acknowledgement}

The authors wish to thank those who graciously gave their time, kind co-operation and encouragement which help us in completion of this study. 


\section{References}

An, Y-J., Haynes, L, D'Alba, A., \& Chumney, F. (2016). Using educational computer games in the classroom: Science teachers' experiences, attitudes, perceptions, concerns, and support needs. Contemporary Issues in Technology \& Teacher Education, 16(4), 415-433.

Bangert-Drowns, R.L., \& Pyke, C. (2002), Educational Technology Resource Development, 50, 23.

Batson, L. \& Feinberg, S. (2006). Game designs that enhance motivation and learning for teenagers. Electronic Journal for the Integration of Technology in Education, 5(1), 34-43.

Bailenson, J. N., Swinth, K., Hoyt, C., Persky, S., Dimov, A., \& Blascovich, J. (2005). The Independent and Interactive Effects of Embodied-Agent Appearance and Behavior on Self-Report, Cognitive, and Behavioral Markers of Copresence in Immersive Virtual Environments. Presence: Teleoperators and Virtual Environments, 14, 379-393

Bailey, R., Wise, K. \& Bolls, P. (2014). How avatar customizability affects children's arousal and subjective presence during junk food-sponsored online video games. CyberPsychology \& Behavior 12(3),277-283.

Barreto, D., Vasconcelos, L., \& Orey, M. (2017). Motivation and Learning Engagement through Playing Math Video Games. Malaysian Journal of Learning and Instruction, 14(2), 1-21.

Baylor, A. L. (2011). The design of motivational agents and avatars. Educational Technology Research and Development, 59(2), 291-300.

Baylor, A. L. (2009). Promoting motivation with virtual agents and avatars: Role of visual presence and appearance. Philosophical Transactions of the Royal Society B: Biological Sciences, 364(1535),3559-3565.

Baylor, A. L. \& Kim, Y. (2004). Pedagogical Agent Design: The Impact of Agent Realism, Gender, Ethnicity, and Instructional Role. In (Eds. J. Lester, et al) Lecture Notes in Computer Science: Intelligent Tutoring Systems, Volume 3220, (pp. 592-603) Berlin/Heidelberg: Springer.

Baylor, A. L., \& Ryu, J. (2003). Does the presence of image and animation enhance pedagogical agent persona? Journal of Educational Computing Research, 28(4), 373-395.

Baylor, A. L. (2000). Beyond butlers: Intelligent agents as mentors. Journal of Educational Computing Research, 22(4), 373-382

Christopoulos, A., Conrad, M., \& Shukla, M. (2018). Increasing student engagement through virtual interactions: How?. Virtual Reality, 1-17.

Clark, R. C., \& Mayer, R. E. (2003). E-learning and the science of instruction proven guidelines for consumers and designers of multimedia learning. John Wiley \& Sons.

Clement, L. (2016). External and internal barriers to studying can affect student success and retention in a diverse classroom. Journal of microbiology \& biology education, 17(3), 351.

Craig, S. D., Gholson, B. \& Driscoll, D. M. (2002). Animated Pedagogical Agents in Multimedia Educational Environments: Effects of Agent Properties, Picture Features, and Redundancy. Journal of Educational Psychology, 94(2), 428-434.

Dai, D., \& Fry, A. (2014). Effect of video games on child development. Developmental Psychology at Vanderbilt.

Dalibard, S., Magnenat-Talmann, N., \& Thalmann, D. (2012, May). Anthropomorphism of artificial agents: a comparative survey of expressive design and motion of virtual characters and social robots. In Workshop on Autonomous Social Robots and Virtual Humans at the 25th Annual Conference on Computer Animation and Social Agents (CASA 2012).

de Borst, A. W., \& de Gelder, B. (2015). Is it the real deal? Perception of virtual characters versus humans: an affective cognitive neuroscience perspective. Frontiers in Psychology, 6, 576.

Dichev, C., \& Dicheva, D. (2017). Gamifying education: what is known, what is believed and what remains uncertain: a critical review. International Journal of Educational Technology in Higher Education, 14(1), 9.

Doerr, N. (2007). Heavy Rain devs have “conquered” the Uncanny Valley. Joystiq.

Retrieved from http://www.joystiq.com/2007/12/18/heavy-rain-devs-have-conquered-theuncanny-valley/

Domagk, S. (2010). Do pedagogical agents facilitate learner motivation and learning outcomes? The role of the appeal of agent's appearance and voice. Journal of Media Psychology: Theories, Methods and Applications, 22(2), 84-97

Ellis, R. (2001). Second Language Acquisition. Oxford, England: Oxford University Press, Sixth Impression., 
Ersoz, A. (2000). Six games for EFL/ESL classroom. The Internet TESL Journal, 6(6)

Evans, M. A., Jones, B. D., \& Akalin, S. (2017). Using Video Game Design to Motivate Students. Afterschool Matters, 26, 18-26.

Franciosi, S. J. (2011). A Comparison of Computer Game and Language-Learning Task Design Using Flow Theory. CALL-EJ, 12(1), 11-25.

Garau, M., Slater, M., Vinayagamoorthy, V., Brogni, A., Steed, A., \& Sasse, A. M. (2003). The impact of avatar realism and eye gaze control on the perceived quality of communication in a shared immersive virtual environment. Proceedings of the SIGCHI Conference on Human Factors in Computing Systems CHI '03 (New York, NY: ACM), 529-536.

Groff, J., Howells, C. \& Cranmer, S. (2010). The impact of games in the classroom: Evidence from schools in Scotland. Learning and Teaching in Scotland. Futurelab. Retrieved from

https://www.nfer.ac.uk/publications/FUTL25/FUTL25.pdf

Gulz, A., \& Haake, M. (2005). Social and visual style in virtual pedagogical agents. In: Proceedings of the Workshop on Adapting the Interaction Style to Affective Factors, 10th International Conference on User Modelling.

Haake, M. (2009). Embodied pedagogical agents: From visual impact to pedagogical implications.

Hays-Roth, B., \& Doyle, P. (1998). Animate Characters. Autonomous Agents and Multi-Agent Systems, 1, $195-230$.

Heinich, R., Molenda, M., \& Russell, J. D. (1993). Instructional media and the new technology of instruction. Macmillan

Huang, H. M., \& Liaw, S. S. (2018). An Analysis of Learners' Intentions Toward Virtual Reality Learning Based on Constructivist and Technology Acceptance Approaches. The International Review of Research in Open and Distributed Learning, 19(1).

Huang, W. H. (2011). Evaluating learners' motivational and cognitive processing in an online game-based learning environment. Computer in Human Behavior, 27(2), 694-704

Hoggins, T. (2010). Heavy Rain video game review. The Telegraph. Retreived from http:/www.telegraph.co.uk/technology/video-games/7196822/Heavy-Rain videogame-review.html

Inal, Y. \& Cagiltay, K. (2006). Avatars as Pedagogical Agents for Digital Game-Based Learning. In C. Crawford, R. Carlsen, K. McFerrin, J. Price, R. Weber \& D. Willis (Eds.), Proceedings of Society for Information Technology \& Teacher Education International Conference 2006 (pp. 3440-3443). Chesapeake, VA: Association for the Advancement of Computing in Education (AACE).

Johnson, W.L., Rickel, J.W. \& Lester, J.C. (2000). Animated pedagogical agents: Face-to-face interaction in interactive learning environments. International Journal of Artificial Intelligence in Education, 11, 47-78.

Kapp, K. (2014). The gamification of learning and instruction: game-based methods and strategies for training and education. San Francisco, CA: Pfeiffer

Kebritchi, M., Hirumi, A., \& Bai, H. (2010). The effects of modern mathematics computer games on mathematics achievement and class motivation. Computers \& Education, 55(2), 427-443.

Kickmeier-Rust, M. D., \& Albert, D. (2010). Micro Adaptivity: Protecting Immersion in Didactically Adaptive Digital Educational Games. Journal of Computer Assisted Learning, 26, 95-105.

Kokkinara, E., \& McDonnell, R. (2015). Animation realism affects perceived character appeal of self-virtual face. Proceedings of the 8th ACM SIGGRAPH Conference on Motion in Games, 221-226.

Krämer, N., Rosenthal-von der Pütten, A., \& Hoffmann, L. (2015). Social effects of virtual and robot companions. In S. Shyam Sundar (Ed.), The handbook of the psychology of communication technology (pp. 137-159). Wiley Blackwell.

Lee, S. P., Badler, J. B., \& Badler, N. I. (2002). Eyes alive. ACM Transactions on Graphics (TOG) (ACM), 21, 637-644

Liu, T. Y., \& Chu, Y. L. (2010). Using ubiquitous games in an English listening and speaking course: Impact on learning outcomes and motivation. Computers \& Education, 55(2), 630-643.

MacDorman, K. F., Green, R. D., Ho, C.-C., \& Koch, C. (2009). Too real for comfort? Uncanny responses to computer generated faces. Computers in Human Behavior. 25, 695-710.

Ma, X., Andalibi, N., Barkhuus, L., \& Naaman, M. (2017, May). People are either too fake or too real: opportunities and challenges in tie-based anonymity. In Proceedings of the 2017 CHI Conference on Human Factors in Computing Systems(pp. 1781-1793). ACM. 
Mert, Y., \& Samur, Y. (2018). Students' Opinions Toward Game Elements Used in Gamification Application. Turkish Online Journal of Qualitative Inquiry, 9(2).

Mori, M. (1970). Bukimi no tani [the uncanny valley]. Energy, 7, 33-35.

Moreno, R., Mayer, R. E., Spires, H. A., \& Lester, J. C. (2001). The case for social agency in computer-based teaching: Do students learn more deeply when they interact with animated pedagogical agents? Cognition and Instruction, 19(2), 177-213.

Norman, D. A. (1994). How might people interact with agents? Communications of the ACM, 37(7), 68-71.

Norman, D. A. (1997). How might people interact with agents. In J. M. Bradshaw (Ed.), Software agents (pp. 49-55). Menlo Park, CA: MIT Press.

Nomura, T., Shintani, T., Fujii, K., \& Hokabe, K. (2007). Experimental investigation of relationships between anxiety, negative attitudes, and allowable distance of robots. Proceeding of the Second IASTED International Conference on Human-Computer Interaction ,13-18.

Nowak, K.L., \& Rauh, C. (2005). Influence of the avatar on online perceptions of anthropomorphism, androgyny, credibility, homophily, and attraction.Journal of computer-mediated communication, 11(1), 153-178.

Pan, X., Gillies, M., \& Slater, M. (2015). Virtual character personality influences participant attitudes and behavior-an interview with a virtual human character about her social anxiety. Frontiers in Robotics and AI, $2,1$.

Papastergiou, M. (2009). Digital game-based learning in high school computer science education: Impact on educational effectiveness and student motivation. Computers \& Education, 52(1), 1-12.

Pesare. E., Roselli, T., Corriero, N., \& Rossano, V. (2016). Game-based learning and gamification to promote engagement and motivation in medical learning contexts. Smart Learning Environments, 3(1), p.5

Prensky, M. (2003). Digital game-based learning. Computers in Entertainment, 1(1), 21-21.

Ratan, R. A., \& Hasler, B. (2011). Designing the virtual self: How psychological connections to avatars may influence education-related outcomes of use. European Immersive Education Summit 1(1), 110-121.

Rankin, Y., Gold, R., \& Gooch, B. (2006). 3D role-playing game as language learning tools. Paper presented at the EuroGraphics 2006, Vienna, Austria.

Ravaja, N., Turpeinen, M., Saari, T., Puttonen, S., \& Keltikangas-Järvinen, L. (2008). The psychophysiology of James Bond: Phasic emotional responses to violent video game events. Emotion, 8(1), 114-120

Rizzo, P. (2000). Why should agents be emotional for entertaining users? A critical analysis. In A. M. Paiva (Ed.), Affective interaction: Towards a new generation of computer interfaces (pp. 166-181). Berlin: SpringerVerlag.

Reschly, A.L., \& Christenson, S.L. (2012). Handb. Res. Student Engagem, 3-1.9

Romero, L., \& Glass, M. (2015). Learning by doing: Creating engaging online learning. Educational Technology, 35-39.

Shaked, N. A. (2017). Avatars and virtual agents-relationship interfaces for the elderly. Healthcare technology letters, 4(3), 83-87.

Sheth, R. (2003). Avatar Technology: Giving a Face to the e-Learning Interface. The Elearning Developers

Schunk, D. H., \& Mullen, C. A. (2012) Self-efficacy as an engaged learner. Handbook of research on student engagement, 219-235.

Schroeder, N. L., Adesope, O. O., \& Gilbert, R. B. (2013). How effective are pedagogical agents for learning? A metaanalytic review. Journal of Educational Computing Research, 49(1), 1-39.

Skinner, E.A., Kindermann, T. A., Connell, J. P., \& Wellborn, J. G. (2009). Engagement and disaffection as organizational constructs in the dynamics of motivational development. Handbook of motivation at school,.223-245

Strafling, N., Fleischer, I., Polzer, C., Leutner, D., \& Kramer, N. C. (2010). Teaching Learning Strategies with a Pedagogical Agent: The Effects of a Virtual Tutor and its Appearance on Learning and Motivation. Journal Of Media Psychology: Theories, Methods, and Applications, 22(2), 73-83

Tinwell, A. (2015). The uncanney valley in games and animation. New York: CRC Press.

Tinwell, A. (2013) '3D graffiti: Virtuality to the streets', in Borriello, L. \& Ruggiero, C. (eds) Inopinatum: Urban Creativity. Rome: Artigrafiche Bocchia, 119 - 213. 
Uzun, L., Cetinavci, U.R., Korkmaz, S., Salihoglu, U.M. (2013). Developing and applying a foreign language vocabulary learning and practice game: The effect of VocaWord. Digital Culture Education 5(1), 48-70

Vassileva J., Deters R., Greer J., McCalla G., Kumar V., Mudgal C. (1998) A Multi-Agent Architecture for Peer-Help in a University Course, Proc. Workshop on Pedagogical Agents at ITS'98, San Antonio, Texas, 64-68.

Vinayagamoorthy,V., Steed,A., and Slater,M. (2008). The impact of a character posture model on the communication of affect in an immersive virtual environment. Computer, 14, 1-17.

Vinayagamoorthy, V., Garau, M., Steed, A., and Slater, M. (2004). An eye gaze model for dyadic interaction in an immersive virtual environment: practice and experience. Computer Graphic Forum ,23, 1-11.

Vinayagamoorthy, V., Brogni A., Steed A., \& Slater M. (2006). The role of posture in the communication of affect in immersive virtual environments. In The 2nd ACM SIGGRAPH International Conference on Virtual Reality Continuum and Its Applications.

Wilkinson, P. (2013). Affective educational games: Utilizing emotions in game-based learning. 5th International Conference on Games and Virtual Worlds for Serious Applications (VS-GAMES), pp. 1-8.

Yang, Y.-T. C. (2012). Building virtual cities, inspiring intelligent citizens: Digital games for developing students' problem solving and learning motivation. Computers \& Education, 59(2), 365-377.

Yee, N. (2006). Motivations for play in online games. Cyber-Psychology Behavior, 9, 772- 775.

Zanbaka, C. A., Ulinski, A. C., Goolkasian, P., \& Hodges, L. F. (2007). Social responses to virtual humans: implications for future interface design. Paper presented at the Proceedings of the SIGCHI conference on Human factors in computing systems. 